\title{
On Application of Memetics to English Translation Teaching in China's Higher Vocational Institutes
}

\author{
Yujie $\mathrm{Nie}^{1, \mathrm{a}}$ \\ ${ }^{1}$ Foreign Language Department of Guangzhou City Polytechnics, Guangzhou 510405 \\ ${ }^{a}$ email
}

Key Words: Memetics; Translation Teaching; China’s Higher Vocational Institutes; Non-English Majors

\begin{abstract}
This thesis analyzes current English translation teaching situation in China's higher vocational non-English majors education. Problems are pointed out such as: ignorance of an overall language learning but stress on only career jargons or professional terms; failure to help students deliver proper translation by applying language variations. Memetics is adopted to probe into possible solutions. Tentative suggestions like "to restore the value of memorization" and "awareness of context"are made to aim at an improvement on the existing matters.
\end{abstract}

\section{Research Background}

It is an acknowledged objective in China's higher vocational education that college teaching must aim at developing students' occupational aptitudes that qualify themselves in their future posts at work. College English teaching to non-English majors in these vocational institutes is career oriented, targeting at promoting students' competence of making communication or presentation in occupational English in different careers. As one of the five aspects of English proficiency, translation proficiency is receiving increasing attention and stress as students are likely to engage in cross-cultural communications in their future work more frequently than ever in a era of globalizaion and China's all-round exchange with the outside world.

As an experienced English teacher in one of China's higher vocational institutes, the author finds out, through teaching and exchanging with peers, that most vocational college students' translation proficiencies turn out not so satisfactory. Main problems are: they are not able to make a complete, half grammatically correct translation; and they don't have a systematic comphrension of translation skills and techniques, which makes every translation sample an isolated reference but do not serve as guidance to their future translation practice. In view of this, the author hopes to develop some teaching ideas or strategies as possible solutions under the theoretic framework of Memetics, which is a theory for interpreting cultural evolution and has provided valuable insights to a number of memetic translation studies.

\section{Literature Review}

Memetics was put forward by Dawkins in 1976. It’s key word "meme" was coined to display a resemblance with "gene” as was borrowed from Darwin's evolution theory. Memes are genes of culture; They may be a cultural image or a cultural phenomenon. Popular slogan, tag lines, inventions, vogue, ideas or behaviors all the rage at one time are various possible forms of memes. In nature, a meme 
consists of two features: a meme is a "unit of cultural transmission" as well as a "unit of imitation" (Dawkins, 2006: 192). The latter one is emphasized and elaborated by Dawkins as in his opinion, a meme transmits/replicates itself through imitation. While in the process of transmission, a meme is likely tochange so as to fit time or another culture, hence a variation of it arises. As one form of meme's carrier, language helps transmit human cultures from brain to brain, from brain to book and vice versa, across countries and generations. On the other hand, memes contribute to language enrichment and development.

In 1997, Finland scholar Chesterman published a book Memes of Translation and introduced Memetics into translationstudies for the first time. He places a lot of importance on theoretical concepts, norms, strategies and values and regards them as the most important types of memes. SusanBlackmore made contributions to the development of Memetics at the same time with Chesterman. Her bookThe Meme Machine(1999) was dedicated to the real practice of Memetics to illustrate social phenomena such as religion, language and altruism on the basis of the hypothesis of memes.

Professor GUI Shi-chun is the first person in China to introduce Memetics to the field of linguistics.He mentioned the concept of meme briefly and suggested possibilities of Memetic application in linguistic research in 2002 when he wrote preface for a book.

After that, professor HE Zi-ran published a series of articles to introduce Memetics into China's linguistic study. He believes that the theory sheds a new light in pragmatics and is bound to make great significance once it is combined with studies of applied linguistics, culture, translation, and second languge aquisition. A number of Chinese scholars and researchers have made various studies on it since then and dissertations, theses published found English writing and translation the most popular field covered by researchers.

\section{Memetics and English Translation Teaching to China's Vocational Institute}

\section{non-English Majors}

Past decades witnessed a variety of new theories, approaches, models and methods appearing in second language teaching and learning area. Opposing or challenging the traditional way of teaching, some of them stress instructional, enjoyment, student-initiative side of teaching. The traditional way of memorizing in learning language appear and is considered to be dull and old-fashioned. While memorization is about to be left out, memetics renders renewed insight in language learning and drums support for the old method in that language memes replication and transmission cannot do without learner's memorization of that language. Be it words, phrases, structures, or styles of language, only when learners can repeat those from memory does one language pass on to another different culture. For translators, a large memory of authentic second language patterns, structures, usages ensure a quality translation.

But when it comes to C-E translation teachings and practice explanation in China's vocational institutes, facts are that jargons, terms, fixed expressions are singled out for students to recite and meorize. Due to reletively poor proficiency in English and comphrension ability in understanding theories, vocational school students are freed from strict grammatical training and systemetic translation skill learning. Thus the above mentioned method becomes what is left in translation classes in most of the time. Students learning translation under this method grasp a large number of professional, techinical terms, but fail to deliver a fluent, idiomatic, or even complete long semantic unit. For example, in translating a Chinese sentence meaning "The player can handle a wide range of formats, with enough space to store around 300 audios” into English. Chinese students knowing terms “format”,"audio/track” but lacking 
storage of vocabulary and structure to connect those key words may produce a translation as "Theplayer many formats, play 300 audios/tracks.” Danger of this do-not-see-forest-for-the-trees teaching method lies in that translation teaching turns students into shabby and lame communicators, and makes it difficult for them to meet a higher requirements in terms of language proficiency.

Translation process, according to memetics, can be considered as a way of language meme transmission and immitation. Only when such immitation-- translator's encoding in target language is accepted and then spread by target readers do language memes transmit. HE Zi-ran(2005:64) holds that there are two ways formemes to be replicated and transmitted: the same core content being inherited in various forms, andthe identical set pattern being followed by different contents. The former is of memetic genotype,andthe latter memetic phenotype. Appling the view to translation, one can enhance his translation skills by: expressing the same meaning in as various forms as possible, and using a sentence pattern, grammar structure to convey different meanings in varied contexts. These are all possible because language memes vary in the process of transmission.

In English translation teaching, teachers are responsible to remind students of the above mentioned theoretic findings, and because of which, context should be brought to mind when there is necessity to make choices on one correct form from varied ones expressing an identical meaning. For instance, students majoring in secretary may know that to take a telephone message, one has to write simply as "Mr. Black called to cancel the appointment. Make it another date\&time”. Context changes, however, as the secretary reports the message to her manager in note or orally. The same meaning needs a different languge form to make it sound professional and polite. If vocational institute students are asked to mock the task and translate the meaning from Chinese to English, they are supposed to be trained on aspects of full consideration of context due to variations resulted from language memes' transmission into different times and spaces. So a proper translation may be "Mr. Black called and would like to cancel his appointment with you. He wonders if you could schedule another date and time to meet him.

\section{Conclusion}

Memetics, in its essence, is a theory about cultural transfer, cultural evolution and cultural similarity. (Chesterman, 2009) It points out that language, as one form of memes, spread itself and the culture it carries through transmission across spaces, generations. Translation Memetics sees translation a process of language memes' transmission and immitation first by translator and then by receptors. From this perspective, a translation learner, in its initial learning stage, is adviced to immitate the second language in a "word-for-word" memorizing method to ensure an idiomatic translation. This fits the condition of China's higher vocational college students and will benefit their translation proficiency in view of current problems existing in translation teaching and learning.

\section{Reference}

[1] Blackmore, S.The Meme Machine [M]. Oxford: Oxford University Press, 1999

[2] Chesterman, A.Memes of Translation: The Spread of Ideas in Translation Theory M]. Amsterdam: John Benjamins, 1997.

[3] Chesterman A. The view from Memetics [J]. Paradigmi, 2009(2):75-88.

[4] Dawkins R. The Selfish Gene [M]. New York: Oxford University Press,2006:192,

[5] FU Shu-jing. The Study of English Major's Translation Theory Teaching Based on Translation Memetics [D]. Jinan:Shangdong Normal University, 2014. 
[6] HE Zi-ran,HEXue-lin. MemeticsandSocialUsageofLanguage[J].Modern Foreign Languages, 2003(2).

[7] HE Zi-ran. Memes in Language [J]. Linguistic Sciences, 2005, (6).

[8] HU Ming-Shuang. A Study on Translation Teaching in New CET-4 from the Perspective of Memetics [D]. Dalian: Liaoning Normal University, 2014.

[9] MA Xiao. Translation Memetics and Translation Teaching [J]. Shangdong Foreign Languages Teaching Journal, 2005(3). 